\title{
Cord serum albumin as a predictor of neonatal hyper bilirubinemia in healthy full-term neonates
}

\author{
Dhanjal G.S. ${ }^{1}$, Rathi R.K. ${ }^{2}$, Agrawal S. ${ }^{3}$, Savita $^{4}$ \\ ${ }^{1}$ Dr. Gurdeep Singh Dhanjal, Professor, Department of Pediatrics, ${ }^{2}$ Dr. Rajesh Kumar Rathi, $3^{\text {rd }}$ year PG Resident, \\ Department of Pediatrics, ${ }^{3}$ Dr. Sonam Agrawal, Senior Resident, Department of Pediatrics, ${ }^{4}$ Dr. Savita, Senior Resident, \\ Department of Obstetrics and Gynecology, all authors are affiliated with Maharishi Markandeshwar Institute of Medical \\ Sciences and Research, Mullana, Ambala, Harayana, India.
}

Corresponding Author: Dr. Rajesh Kumar Rathi, MMIMSR, Mullana, Ambala. Email: drrajeshrathi88@gmail.com

\begin{abstract}
Introduction: Neonatal jaundice or icterus neonatorum is one of the common problem that is seen in newborns during first week of neonatal life. Clinical jaundice is found in about $80 \%$ of preterm and in about $60-70 \%$ of term neonates. The main objective of the study was to determine the correlation between cord serum albumin levels and development of significant hyper bilirubinemia in healthy term neonates. Methods: A prospective study was conducted on 316 healthy term neonates. Gender, mode of delivery and birth weight were taken into consideration. It was ascertained that there was no other risk factor for neonatal hyperbilirubinemia among these newborns. These neonates were divided into 3 groups, Group A (cord serum albumin levels $<2.8 \mathrm{gm} / \mathrm{dl}$ ), Group B (cord serum albumin levels between 2.8 to $3.4 \mathrm{gm} / \mathrm{dl}$ ) and Group C (cord serum albumin levels $>3.4 \mathrm{gm} / \mathrm{dl}$ ). Result: Of the 316 babies included in the study, 102 babies were under Group A, 166 babies under Group B and 48 babies under Group C. 35 babies in Group A, 5 in Group B and none in Group $\mathrm{C}$ developed significant hyperbilirubinemia and required phototherapy. The sensitivity and specificity of cord serum albumin level $<2.8 \mathrm{~g} / \mathrm{dl}$ to predict risk of development of significant neonatal hyperbilirubinemia in our study was $87.50 \%$ and $75.72 \%$ respectively. Conclusion: Cord serum albumin levels can help us to predict the possibility of significant hyperbilirubinemia among neonates. Hence this can help us to identify the at-risk neonates and utilize our limited resources efficiently among these newborns.
\end{abstract}

Keywords: Cord serum albumin, Hyperbilirubinemia, Icterus neonatorum

\section{Introduction}

Neonatal jaundice or icterus neonatorum is one of the common problems that are seen in newborns during first week of neonatal life [1]. Clinical jaundice is found in about $80 \%$ of preterm and in about $60-70 \%$ of term neonates [2]. More than $6.1 \%$ of term neonates were found to have bilirubin level more than $12.9 \mathrm{mg} / \mathrm{dl}$ and $3 \%$ of term neonates had bilirubin level more than 15 $\mathrm{mg} / \mathrm{dl}$ [3]. In India incidence of neonatal hyper bilirubinemia varied from $4.3 \%$ to $6.5 \%$ of all live born babies [4]. Neonatal hyper bilirubinemia is the commonest cause of readmission in early neonatal period in about $6.5 \%$ cases [1].

In current clinical practice, healthy term newborns after normal delivery are discharged earlier due to either medical reasons to prevent them from nosocomial

Manuscript received: $8^{\text {th }}$ April 2018

Reviewed: $18^{\text {th }}$ April 2018

Author Corrected: $25^{\text {th }}$ April 2018

Accepted for Publication: $30^{\text {th }}$ April 2018 infections, social reasons like early naming ceremony or due to financial constrain. As per American Academy of Pediatrics Recommendations, the new borns discharged before 48 hours of birth should be followed between 48 to 72 hours of birth to rule out significant neonatal jaundice and other problems [5]. In our country because of limited follow up facilities such close monitoring is usually not feasible and due to poor follow up, sometime the newborn with significant neonatal jaundice may be missed or the treatment delayed, resulting in brain damage of these newborn.

The main concern regarding early discharge are reports of bilirubin induced brain damage in healthy term neonates even without hemolysis. Though the exact total serum bilirubin (TSB) level that leads to development of kernicterus in icteric newborn is not known, A bilirubin level greater than $20 \mathrm{mg} / \mathrm{dl}$ is found to be associated with development of kernicterus and 
may cause severe form of brain damage [1]. Defining a certain bilirubin level as physiological can be misleading and potentially dangerous. It is difficult to predict the course of hyperbilirubinemia on day one of a neonate. The concept of prediction of jaundice offers an attractive option to pick up babies at risk of developing significant neonatal hyperbilirubinemia.

Till date only few predictors of neonatal jaundice have been studied, these are cord blood albumin, cord blood bilirubin, cord blood albumin to bilirubin ratio and alpha-fetoprotein [6]. By predicting the newborns developing significant neonatal jaundice early at birth, we can design and implement the follow-up of the highrisk groups cost effectively. In this way early treatment could be started, which could reduce the risk of bilirubin dependent brain damage. There is paucity of studies on cord serum albumin (CSA) as a predictor of severity of neonatal hyper-bilirubinemia, hence our study was aimed to evaluate the predictive value of cord serum albumin as predictor of significant neonatal hyperbilirubinemia in healthy term neonates and subsequent requirement of phototherapy or exchange transfusion.

\section{Materials and Methods}

Study design- Prospective study

Study center- Department of Pediatrics, Maharishi Markandeswar Institute of Medical Sciences and Research (MMIMSR) Mullana, Ambala (Haryana)

Period of study- September 2015 to February 2017

Ethical clearance was obtained from the institutional ethical committee.

Sample size- When the prevalence of neonatal jaundice patients was assessed with precision error of estimation (d) $=0.03$, and alpha $=0.05$, a sample size of at least 100 cases was needed to estimate the incidence.

Study population- The study was conducted on 316 healthy newborns with the following criteria

\section{Inclusion criteria}

- Term newborns

- Birth weight $\geq 2.5 \mathrm{~kg}$.

- $\operatorname{APGAR} \geq 7 / 10$ at $1 \mathrm{~min}$

\section{ExclusionCriteria}

- Preterm,

- Out born neonates
- Rh incompatibility

- ABO incompatibility

- Instrumental delivery (forceps and vacuum)

- Hemolyticanemia(G6PD,Hereditaryspherocytosisetc)

- Birth asphyxia

- Newborn with major congenital malformation,

- Neonatal sepsis

- Neonatal jaundice within 24 hours of life

- Neonatal hypothyroidism

- Meconium aspiration and babies on drugs like phenobarbiturates

Methodology and Sampling method- A detailed maternal and neonatal history was taken as per the prescribed Performa. The recruited mother of the neonates were assessed in detail as regards the gestational age, blood group, parity, oxytocin infusion, maternal risk factors like premature rupture of membrane, meconium stained liquor, sepsis, fever, oligo-hydroamios, and mode of delivery. The clinical examination of the newborn was done at the time of delivery and thereafter regularly during the hospital stay.

$2 \mathrm{ml}$ of umbilical cord blood as collected from all newborns included in my study and measurement of cord serum albumin levels is done by an auto analyzer "SIEMENS Dimension clinical chemistry system Flex reagent cartridge Albumin method".

Based on the levels of cord serum albumin these neonates were further divided into 3 groups:

CSA Group A: Cord serum albumin levels $<2.8 \mathrm{gm} / \mathrm{dl}$

CSA Group B: Cord serum albumin levelsbetween2.8 to $3.4 \mathrm{gm} / \mathrm{dl}$

CSA Group C: Cord serum albumin levels $>3.4 \mathrm{gm} / \mathrm{dl}$

The normal range for cord serum albumin in term babies is $2.8-3.4 \mathrm{gm} / \mathrm{dl}$.

For estimation of total serum bilirubin (TSB) $2 \mathrm{ml}$ of venous blood from babies included in the study was collected at 24 hours, between 3-5 days and thereafter if required for estimation of total serum bilirubin and results were obtained by automatic analyzer "SIEMENS Dimension clinical chemistry system Flex reagent cartridge Total Bilirubin method". These neonates were followed up daily for sign and symptoms of development of jaundice till $5^{\text {th }}$ day of life, because serum bilirubin levels reach its peak between $3^{\text {rd }}$ to $5^{\text {th }}$ day in term healthy neonates. 
Significant neonatal hyperbilirubinemia in our study was defined as bilirubin levels $\geq 14 \mathrm{gm} / \mathrm{dl}$ as per AAP guideline normogram [5]. The data was entered into the performa in which the gender, gestational age, mode of delivery, anthropometric measurements at birth, cord serum albumin and total and direct bilirubin of the babies were noted. The main outcome of the study was inferred in terms of neonatal hyperbilirubinemia.
Statistic Analysis: The analysis was done using the SPSS Version 21. Statistical data were analysed with $\mathrm{t}$ test, chi-square test and ANOVA. Sensitivity, specificity, negative and positive predicative value of the tests was calculated. The cord albumin levels having highest specificity and sensitivity was determined with the Receiver operating characteristics (ROC) curve analysis. The $\mathrm{p}$ value with significance of less than 0.05 were considered statistically significant.

\section{Results}

In the study a total of 316 neonates were registered. Out of these $182(57.59 \%)$ were male and $134(42.41 \%)$ were female. There was no statistically significant difference in the number of male and female babies. The mean gestational age in our study was $38.65 \pm 1.19$ weeks and the mean weight was $2.94 \pm 0.32 \mathrm{~kg}$. Out of 316 babies $163(51.58 \%)$ babies were born by LSCS and $153(48.42 \%)$ were vaginally delivered, with no significant difference among the babies developing significant hyperbilirubinemia based on the mode of delivery. Oxytocin was used in 171 (54.11\%) mothers for either induction or augmentation of labor, no correlation was found between oxytocin use and development of significant hyperbilirubinemia $(\mathrm{p}>0.05)$.

Depending on the cord serum albumin levels the babies were divided into 3 groups, Group A (CSA $<2.8$ gm/dl), Group B (CSA between $2.8 \mathrm{gm} / \mathrm{dl}$ to $3.4 \mathrm{gm} / \mathrm{dl})$ and Group C (CSA > $3.4 \mathrm{gm} / \mathrm{dl})$. There was a total of $102(32.28 \%)$ babies in Group A, 166 (52.53\%) babies in Group B and 48 (15.19\%) babies in Group C.In our study population there was no statistically significant correlation between parity, gender, mode of delivery among CSA groups ( $p$ value $>0.05$ ). In the present study based on severity of hyperbilirubinemia, neonates were put under two groupsone with bilirubin level $\geq$ $14 \mathrm{mg} / \mathrm{dl}$ (significant hyperbilirubinemia) and other with total serum bilirubin level $<14 \mathrm{mg} / \mathrm{dl}$. Out of total 316 healthy term newborns in our study, 40 newborns (12.66\%) had total serum bilirubin $>14 \mathrm{mg} / \mathrm{dl}$, while $276(87.34 \%)$ had total serum bilirubin levels $<14 \mathrm{mg} / \mathrm{dl}$ and correlation between significant hyperbilirubinemia with CSA groups was measured. The correlation between significant hyperbilirubinemia and cord serum albumin groups was found to be statistically significant ( $p$ value $<0.0001$ ) which means, "lower serum albumin is associated with higher chances of development of significant neonatal hyperbilirubinemia"(Table 1).

Table1: TSB- Total serum bilirubin, CSA- Cord serum albumin. Relation between cord serum albumin and TSB.

\begin{tabular}{|c|c|c|c|c|c|}
\hline TSB Groups & $\begin{array}{c}\text { CSA Group A } \\
\text { n ( \%) }\end{array}$ & $\begin{array}{c}\text { CSA Group B } \\
\text { n ( \%) }\end{array}$ & $\begin{array}{c}\text { CSA Group C } \\
\text { n (\%) }\end{array}$ & $\begin{array}{l}\text { Total } \\
\text { n ( } \%)\end{array}$ & P value \\
\hline $\mathrm{TSB}<14 \mathrm{mg} / \mathrm{dl}$ & $67(24.28 \%)$ & $161(58.33 \%)$ & $48(17.39 \%)$ & $276(100 \%)$ & \multirow{3}{*}{$<0.0001$} \\
\hline $\mathrm{TSB} \geq 14 \mathrm{mg} / \mathrm{dl}$ & $35(87.50 \%)$ & $5(12.50 \%)$ & $0(0 \%)$ & $40(100 \%)$ & \\
\hline TOTAL & $102(32.28 \%)$ & $166(52.53 \%)$ & $48(15.19 \%)$ & $316(100 \%)$ & \\
\hline
\end{tabular}

Out of 316 neonates enrolled in the study 40 (12.66\%) developed significant hyperbilirubinemia requiring phototherapy and none of the neonate in our study required exchange transfusion.

The sensitivity of CSA level $<2.8 \mathrm{~g} / \mathrm{dl}$ to predict risk of development of neonatal hyperbilirubinemia in our study was $87.50 \%$ and specificity was $75.72 \%$ while positive predictive value (PPV) was $34.31 \%$ and negative predictive value (NPV) was $97.66 \%$. Correlation of CSA level $<2.8 \mathrm{~g} / \mathrm{dl}$ to predict risk of development of significant neonatal hyperbilirubinemia wasstatistically highly significant $(\mathrm{P}$ value $=<0.0001)$.

\section{Discussion}

Jaundice is a common and, in most cases, a benign problem in term neonates. However, in some cases it may progress to significant level to cause brain damage. In these cases, the newborn requires early treatment and if the treatment is delayed the newborn may develop kernicterus which leads to long term morbidity. The present study was done to find the possible correlation of cord serum albumin and development of significant hyperbilirubinemia, so that it could be used as 
a screening tool to identify at risk neonates. In our study $12.66 \%$ of newborns developed significant neonatal hyperbilirubinemia, similar incidence (10-12\%) were noted in studies done by Venkatamurthy et al, Rishav Raj et al and Sandeep Kumar et al $[7,8,9]$. The study group was a uniform representation of both the sex with no statistically significant difference. In present study no significant correlation between gender of neonates and significant hyperbilirubinemia was found. Similar finding was observed by other authors [7,9,10]. However, the studies done by Satrya and Maisels and Kring had found that male babies are at more risk of developing icterus and subsequent intervention for icterus $[11,12]$.

Overall the mean birth weight of our study cohort was $2.94 \pm 0.32 \mathrm{~kg}$ while mean birth weight in a study done by Suchanda Sahu et al was $3.09 \pm 0.16 \mathrm{~kg}$ and in a study by Dawarumpudi et al the median weight was $3.2 \mathrm{~kg}[2,13]$. The correlation between birth weight and CSA groups in our study was statistically significant. This shows thatlower the birth weight, lower are the cord serum albumin levels.

There was no statistically significant correlation between mode of delivery and significant neonatal hyperbilirunemia ( $>0.05)$. Similar finding was observed in studies done by other authors $[2,14,15]$. Out of 40 newborn who develops significant hyperbilirubinemia, $35(87.50 \%)$ were in CSA group A and $5(11.50 \%)$ were in CSA group B and none in CSA group C. The correlation between the cord serum albumin level and development of significant hyperbilirubinemia was statistically significant $(\mathrm{p}<0.001)$. This means that lesser the cord serum albumin levels more is the chances of newborns developing significant hyperbilirubinemia. While analyzing the diagnostic predictability of cord serum albumin levels among group A (serum albumin $\leq 2.8 \mathrm{mg} / \mathrm{dl}$ ) for neonatal hyperbilirubinemia in our study, the sensitivity was $87.50 \%$ and the specificity was $75.72 \%$. The positive predictive values were $34.31 \%$ and the negative predictive value was $97.66 \%$. The same has been depicted in ROC curve shown in figure 1 (AUC = 0.887). In 2011 Suchanda Sahu et al reported $70 \%$ neonates developing significant hyperbilirubinemia had cord serum albumin level less than $2.8 \mathrm{mg} / \mathrm{dl}$ [2]. In 2014 Venkatmurthy et al observed that cord serum albumin $<2.8 \mathrm{gm} / \mathrm{dl}$ had sensitivity of $95 \%$ and specificity of $74 \%$ in predicting significant hyperbilirubinemia. The positive predictive value was $24.68 \%$ and the negative predictive value was $98.97 \%$ [7].

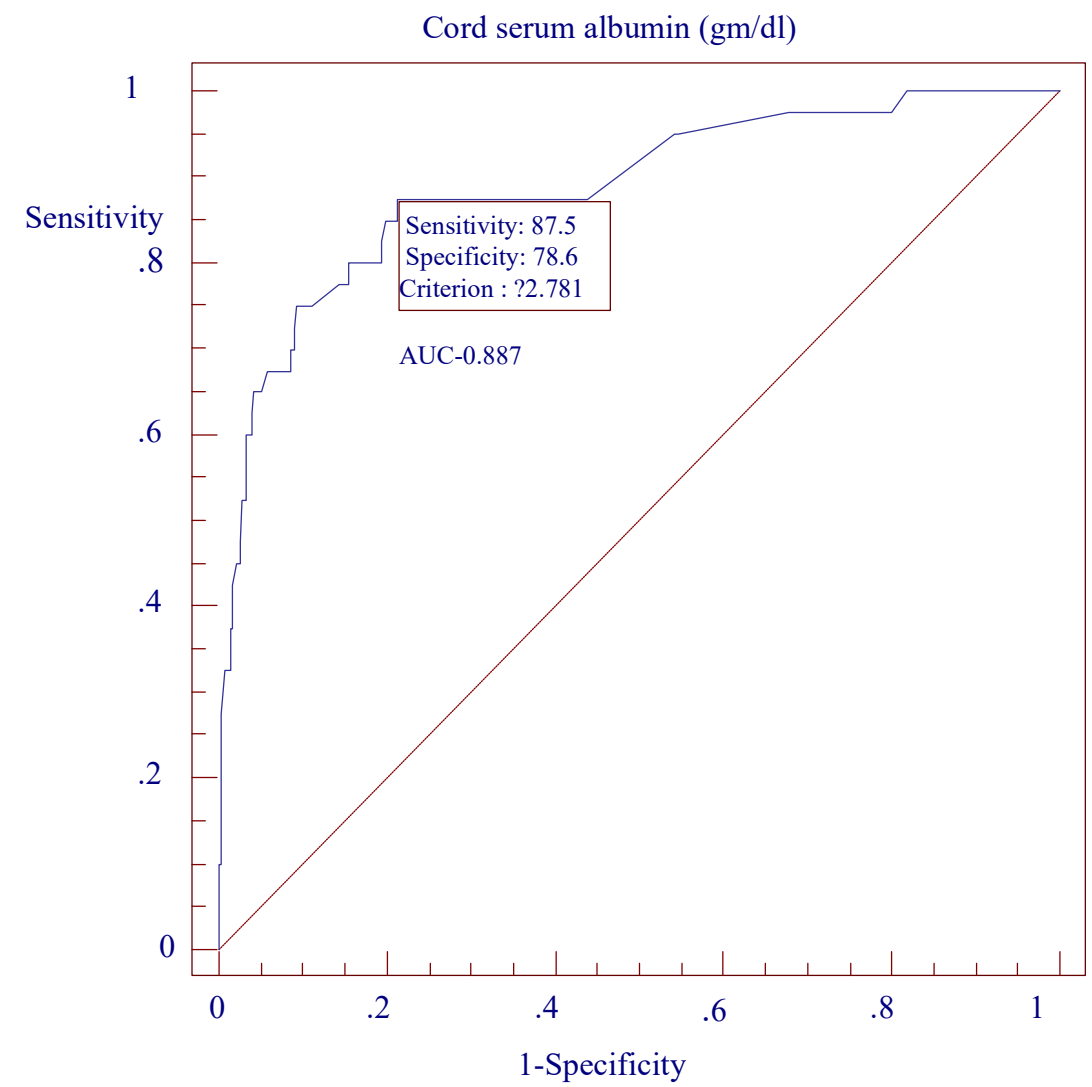

Figure-1: ROC curve. Association between cord serum albumin level and neonatal hyperbilirubinemia 
Neeraj et al found that cord serum albumin $\leq 2.6 \mathrm{gm} / \mathrm{dl}$ had sensitivity of $80 \%$ and specificity of $86.67 \%$ to detect significant hyperbilirubinemia in newborns. The positive predictive value was $40 \%$ whereas the negative predictive value was $97.5 \%$ [16]. In 2016 Sandeep Kumar et al reported that 90 percent of the neonates who developed significant hyperbilirubinemia were having CSA less than $2.8 \mathrm{gm} / \mathrm{dl}[9]$.

Rishav Raj et al found that $95 \%$ of neonates developing significant hyperbilirubinemia had cord serum albumin level $<$ $2.8 \mathrm{gm} / \mathrm{dl}$. The sensitivity of cord serum albumin less than $2.8 \mathrm{gm} / \mathrm{dl}$ to detect hyperbilirubinemia in newborn was $95 \%$, while specificity was $62.34 \%$. The positive predictive value was $24.68 \%$ and the negative predictive value was $98.97 \%$ [8].

Shagun Gupta et al observed that cord serum albumin $<2.8 \mathrm{gm} / \mathrm{dl}$ had sensitivity of $75.93 \%$ and specificity of $68.06 \%$ for detecting significant hyperbilirubinemia in newborn. The positive predictive value was $47.2 \%$ and the negative predictive value was $88.24 \%[17]$.

Aiyappa et al reported the sensitivity of cord albumin to detect hyperbilirubinemia in newborn was determined and found to be $71.8 \%$, while specificity was $65.1 \%$. The positive predictive value was $38.9 \%$ and the negative predictive value was $88.2 \%$. The accuracy rate was $67.3 \%$ and the area under the ROC was $0.684[18]$.

\section{Conclusion}

We conclude that cord serum albuminlevel in healthy term neonate is a useful tool in predicting the possibility of neonatal hyperbilirubinemia. Cord serum albumin give additional clue in predicting the possibility of newborn developing significant hyperbilirubinemia later on.

1. Newborns with cord serum albumin level $<2.8 \mathrm{gm} / \mathrm{dl}$ are at highrisk of developing significant hyper bilirubinemia, which needs treatment and hence they should be followed closely.

2. Newborns with cord serum albumin level $>3.3 \mathrm{gm} / \mathrm{dl}$ has very less probability of developing significant hyperbilirubinemia and can be discharged early from hospital.

\section{Contributions}

- Dr Gurdeep Singh Dhanjal and Dr Rajesh Kumar Rathi wrote first draft of the manuscript.

- Dr Gurdeep Singh Dhanjal, Dr Rajesh Kumar Rathi, Dr Sonam Agrawal and Dr Savita helped in data collection

- Dr Gurdeep Singh Dhanjal, Dr Rajesh Kumar Rathimade final correction of manuscript before submission.

- All authors approved submission of the manuscript and own responsibility of the manuscript. None of the authors have any conflict of interest.

\section{What this study adds to existing knowledge?}

There was no clear cut off value of cord serum albumin level in prediction of significant hyperbilirubinemia. Our study contributes to the fact that a simple cost- effective test like cord serum albumin can go a long way in identifying those newborns who are at risk of developing significant hyperbilirubinemia. In this way we can utilize our limited resources more efficiently.

Funding: Nil, Conflict of interest: None initiated, Perission from IRB: Yes

\section{Bibliography}

1. Cloherty JP, Martin CR. Neonatal hyper bilirubinemia. In: Cloherty JP, Stark AR, editors. Manual of Neonatal Care. 6 th ed. USA: Lippincott Williams \& Wilkins; 2008; 1:181-3.

2. Sahu S, Abraham R, John J, Ann A, Sam A. Cord blood albumin as a predictor of neonatal jaundice. Int J Bio Med Res. 2011; 1(2):436-8.

3. Reshad M, Ravichander B, Raghuraman TS. A study of cord blood albumin as a predictor of significant neonatal hyper bilirubinemia in term and preterm neonates. Int J Res Med Sci. 2016; 4(3):887-90.

4. Neonatal morbidity and mortality: report of the National Neonatal-Perinatal Database. Indian Pediatr. 1997 Nov; 34 (11):1039-42.

5. American Academy of Pediatrics Subcommittee on Hyper bilirubinemia. Management of hyper bilirubinemia in the newborn infant 35 or more weeks of gestation. Pediatrics. 2004 Jul;114 (1):297-316.

6. Pasha YZ, Pour MA, Firouzjahi AR, Dehvari A, Baleghi M, Jahangir T.Umbilical Cord Bilirubin Level 
as a Predictive Indicator of Neonatal Jaundice. J Babol Univ Med Sci. 2015; 17(9):14-8.

7. Venkatamurthy M, Murali S, Hemachandra K. Evaluation of cord serum albumin level as a risk indicator in predicting neonatal Jaundice. Int J Health Info Med Res. 2014;1(2):9-11.

8. Raj RR and Sarangi GD. Cord serum albumin as a tool to predict neonatal hyperbilirubinemia. Index Copernicus International. 2016; 5(3): 131-36.

9. Kumar S, Manjunath G A, Ajay J, Reddy S. Low Cord Serum Albumin is A Risk Indicator in Predicting Neonatal Jaundice. IOSR Journal of Dental and Medical Sciences. 2016; 15 (10): 76-8. (IOSR-JDMS) SLEPije-ISSN: 2279-0853, p-ISSN: 2279-0861.

10. Taksande A, Vilhekar K, Jain M, Zade P, Atkari S, et al. (2005) Prediction of the development of neonatal hyperbilirubinemia by increased umbilical cord blood bilirubin. Ind Medica 9(1): 5-9.

11. Satrya R, Effendi SH, Gurnida DA. Correlation between cord blood bilirubin level and incidence of hyperbilirubinemia in term newborns. Paediatrica Indonesiana. 2009; 49(6):349-54.

12. Maisels MJ, Kring E.Length of stay, jaundice, and hospital readmission. Pediatrics. 1998 Jun;101(6): 995-8.
13. DwarampudiGSand Ramakrishna N. Cord Blood Albumin and Bilirubin Levels As Predictors In Neonatal Hyperbilirubinemia. Int J Pharm Bio Sci 2015 July; 6 (3): (B) 273 - 279.

14. Knudsen A. Prediction of the development of neonatal jaundice by increased umbilical cord blood bilirubin. Acta Paediatr Scand. 1989 Mar;78(2):217-21.

15. Awasthi S, Rehman H. Early prediction of neonatal hyperbilirubinemia. Indian J Pediatr. 1998 Jan-Feb;65 (1): 131-9.

16. Rajpurohit N, Kumar S, Sharma D, Choudhary M, Purohit S. To Assess Predictive Value of Cord Blood Bilirubin and Albumin for Significant Neonatal Hyperbilirubinemia: A Prospective Study from India. J Pediatr Neonatal Care 2(1): 00060. DOI: 10.15406/jpnc. 2015. 02.00060.

17. Gupta S, Gupta VK, Bhatnagar JP, Agrawal P, Agarwal A, Bhatia S et al. Neonatal hyper bilirubinaemia after induction of labour with oxytocin and cord serum albumin is compared with cord serum bilirubin as a risk indicator. International Journal of Biomedical Research 2016; 7(7): 435-8. DOI:10.7439/ ijbr ISSN: 0976-9633; 2455-0566.

18. Aiyappa GKC, Shriyan A, Raj B. Cord blood albumin as a predictor of neonatal hyperbilirubinemia in healthy neonates. Int J Contemp Pediatr 2017;4:503-6.

\section{How to cite this article?}

Dhanjal G.S, Rathi R.K, Agrawal S, Savita. Cord serum albumin as a predictor of neonatal hyper bilirubinemia in healthy full-term neonates. Int J Pediatr Res. 2018;5(4):203-208. doi:10.17511/ijpr.2018.i04.08. 